\title{
To Fragment or to Consolidate Jurisdictions: the Optimal Architecture of Government
}

\author{
Rui Nuno Baleiras \\ Faculdade de Economia \\ Universidade Nova de Lisboa \\ Version of 27 April 2001
}

\begin{abstract}
$\underline{A B S T R A C T}$
Fiscal decentralisation is a hot issue worldwide. Within the European Union, there are even opposing tendencies with respect to the assignment of responsibilities between government tiers. This is a textbook paper aiming to provide a pedagogic introduction to the economics of government formation. Government size and district boundaries are endogenously set. Through a unified diagrammatic framework, the paper stresses the impact many politico-economic factors are likely to exert upon those endogenous variables. The list includes heterogeneity in demand for and supply of local public goods, cost sharing, scale economies, interjurisdictional spillovers, mobility of consumer-voters, congestion degrees, governance costs, and second-best finance. The analysis thus provides a foundation for a vertical system of multifunction governments very much in the pioneering spirit of Mancur Olson and Wallace Oates.
\end{abstract}

Keywords: fiscal federalism, clubs, government size, correspondence principle, governance costs.

JEL's classification codes: D71, D72, H11, H41, H70 and H77.

\footnotetext{
* Correspondence: rnbaleiras@fe.unl.pt; Universidade Nova de Lisboa, Faculdade de Economia, Travessa de Estêvão Pinto (Campolide), P-1099-032 LISBOA, PORTUGAL.; Fax = +351-21 3801600.

I am grateful to Ana Paula Barreira for her insightful remarks. Errors are my own.
} 


\title{
To Fragment or to Consolidate Jurisdictions: \\ The Optimal Architecture of Government
}

\author{
Rui Nuno Baleiras
}

Faculdade de Economia

Universidade Nova de Lisboa

\section{Introduction}

Jurisdiction formation has become an important political issue in the last decade. Former socialist countries entered a process of fragmentation, many West European countries embarked on devolution arrangements, with the empowerment of new, intermediate-level governments in some cases, whereas, at the same time, Member States have transferred new responsibilities to the supranational level of the European Union. Examples outside the continent abound too.

These sometimes-dramatic political changes triggered a new interest on fiscal federalism ideas. After the pioneering work by Mancur Olson and Wallace Oates in the sixties and seventies, ${ }^{1}$ what contribution can economic theory make nowadays to enlighten the rationale behind the fragmentation and consolidation of jurisdictions?

We study the allocation function of the public budget and consider what government level best serves the provision of a local public good. In this sense, jurisdiction fragmentation (consolidation) involves the assignment of the provision responsibility to lower (upper)-level governments, i.e., to governments defined over a subset of (set larger than) the original community. Jurisdiction fragmentation (consolidation) can thus be interpreted as fiscal decentralisation (centralisation) and applies both to political secession (integration) movements and to new intergovernmental assignments within given national borders.

The politico-economic environment clearly influences jurisdiction formations but does so in a contradictory fashion. A number of factors push towards greater fiscal decentralisation whereas other arguments favour the provision by higher-tier governments. Hence, there should be an optimal administration level to deal with a particular responsibility. This remark renders district borders and government size endogenous variables.

\footnotetext{
${ }^{1}$ Olson (1969) and Oates (1972) are perhaps the founders of fiscal federalism. The current paper owes a lot to the spirit of these references.
} 
This paper is part of the author's ongoing textbook project on the economics of multilevel governance. Through a unified framework, it offers a synthesis of the forces shaping the optimal jurisdiction size. As this size differs across public goods, the analysis provides also a foundation for the vertical architecture of government, with the several layers corresponding to different (optimal) jurisdiction sizes.

In what follows, we will focus on the expenditure side of the budget and the reader may wonder why talking about optimal decentralisation degree without looking with similar detail at the revenue side. The reason springs from the fact that expenditure decentralisation is the leitmotiv underlying the very existence of subnational governments. On the one hand, allocation is the single fiscal function where decentralisation may clearly enhance social welfare. On the other, the provision of public goods, either pure or impure, makes up most of the allocation function. Revenue decentralisation is basically an instrument of expenditure decentralisation, and for two reasons. First, a revenue decentralisation goal in itself is meaningless. What sense does it make to enact a local government with the single purpose of collecting taxes on behalf of the central government? If it makes no expenditure and retains no earnings out of that collection, the local authority has no incentive to behave independently. In fact, it would be nothing more than an agent of the central government. Second, once the public good provision is decentralised, transfers from the central governmental rarely happen to be the optimal finance. As we made clear elsewhere, ${ }^{2}$ a variety of own local revenue is, in general, superior. Thus, revenue decentralisation helps to maximise the net benefits of expenditure decentralisation; as such, it is an instrument rather than a goal of local governance. Anyway, in our optimal government-size framework below, we will find a way to embody the welfare contribution of revenue decentralisation.

The paper is organised as follows. First, we explain the incentives each individual faces to approach someone else for the joint provision of a public good. A collective decision to provide one good jointly entails always one benefit and one cost for each participating individual. We label them the basic benefits and costs from fiscal centralisation. Their matching offers a preliminary approximation to the optimal governmental size. Second, one section after another, we will add several new benefit and cost elements to the basic framework and see what their impact upon he optimal size isthese elements are scale economies, interjurisdictional spillovers, population mobility, governance costs, and second-best finance. Third, we will assess a few times the so-called correspondence principle of fiscal decentralisation. As new elements are brought into the

${ }^{2}$ Baleiras (2001), Ch. 6. 
picture, the correspondence between the government size and the number of individuals benefiting from the public good provision becomes increasingly imperfect.

For the sake of convenience, the main results are underlined in a proposition layout. Their proof is geometric most of the time although an algebraic replica is always feasible. Each element entails a utility impact measured by the change in consumer's surplus. The social welfare shock corresponds to the summation of this change across all individuals.

\section{Basic Social Benefits and Costs of Fiscal Centralisation}

In what follows, we are going to use the individual consumer's surplus to measure welfare changes from varying the price of the public good $g$. We will assume a quasilinear utility function for individual $j$,

$$
U\left(y_{j}, g \mid=y_{j}+u \dot{i g}\right)
$$

where $y_{j}$ is individual $j$ 's choice of private $\operatorname{good}$ and $u(\cdot)$ is a twice continuously differentiable function with $u^{\prime}>0$ and $u^{\prime \prime}<0$. With function (1) and a given income level, the change in consumer's surplus reflects exactly the utility impact of any price variation. Moreover, the (unweighted) summation across all individuals of changes in consumer's surplus is an exact measure of social welfare changes. If the utility function is not quasilinear, everything still holds approximately. ${ }^{3}$

When consumers consolidate to consume one good jointly, they face both a utility gain and a utility loss. In what follows, we will use the change in consumer's surplus to identify these basic incentives underlying consumer consolidation.

\section{$2.1 \quad$ The cost-sharing benefit from user pooling}

Figure 1 displays an individual demand curve for the public good $g$. When the price charged to this consumer $(j)$ decreases from $p_{0}$ to $p_{N}$, her surplus increases by the shaded trapezoidal area below the demand schedule $D_{j}{ }^{4}$

\footnotetext{
${ }^{3}$ Additional details in footnote 4. See Varian (1992), pp. 164-166 and 168-169 for proofs.

${ }^{4}$ By definition, the change in consumer's surplus is measured below the ordinary (or Marshallian) demand curve, while the equivalent and the compensating variations of income (two alternative money metric functions) are computed below the compensated (or Hicksian) demand curves. For a quasilinear utility function, the three welfare change measures are exactly the same because there are no income effects to care
} 


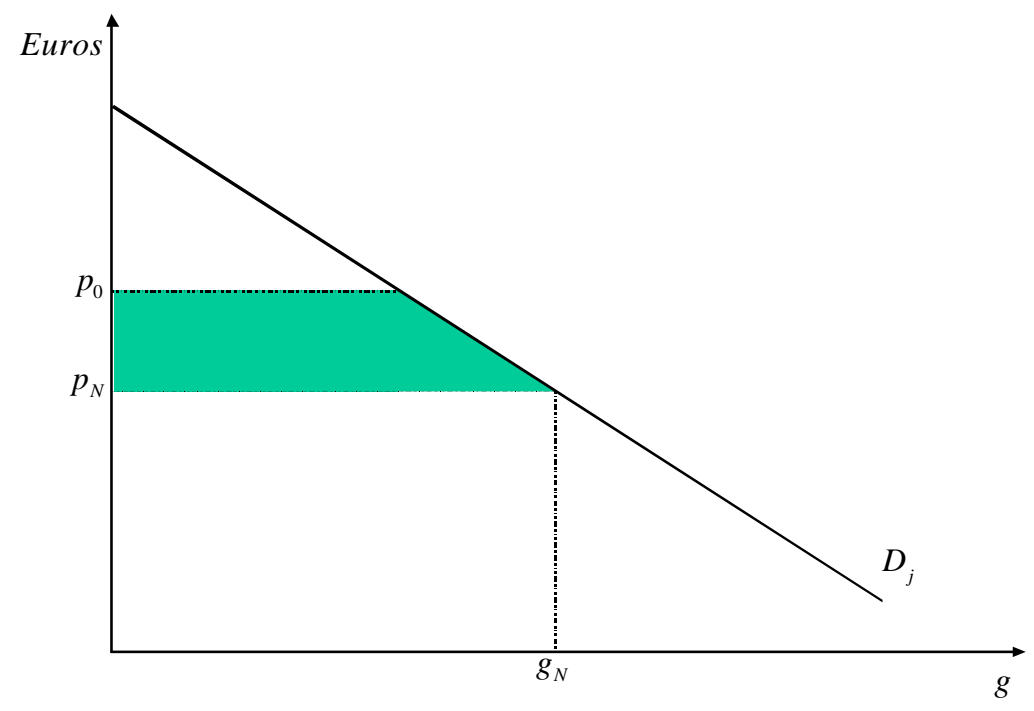

Figure 1-Individual cost-sharing benefit

Let us interpret the two prices in the following way. Suppose $p_{0}$ is the price charged to individual $j$ when she pays the provision cost alone. By sharing this cost with other individuals, her charge per unit drops. If the marginal cost remains at $p_{0}$ and $N$ individuals now contribute to financing the provision cost, the price charged to each one decreases to $p_{N} \equiv p_{0} / N$. The cost sharing of the public good thus gives consumer $j$ a utility gain measured by the change in her surplus. This utility gain is higher the larger is $N$, the pool of contributors. If the additional contributors also consume the good, then they also enjoy an improvement in their surplus. By summing up the trapezoidal areas across all consumers, we get a measure of the social welfare gain. The welfare increases definitely with the number of consumers and this effect is captured by curve $B$ in Figure 2.

Hence, by consolidating the number of consumers, the individual cost share drops and more units of the public good can be consumed by everyone. The aggregate costsavings from increasing the number of individuals who jointly finance the provision are represented by curve $B$; its height depicts the sum of the increase in individual consumer's surpluses. Curve $B$ thus displays the social benefits from consumer consolidation or joint provision.

Footnotes, continued from previous page

about—from the Slutsky's equation, note that this implies the two demand concepts have the same slope. For more general utility functions, the change in consumer's surplus is a reasonable approximation to welfare changes as it is always bounded by the equivalent and the compensating variations of income. 




Figure 2-The basic social benefit from consumer consolidation

To understand the slope of curve $B$, note that its height (like the corresponding consumer's surplus) is proportional to the price drop associated to consolidation. For a constant marginal provision cost $p_{0}$, the price drop $\left(d_{N}\right)$ is simply

$$
d_{N} \equiv p_{0}-p_{N}=p_{0}-\frac{p_{0}}{N}
$$

with

$$
\begin{aligned}
& \frac{\partial d_{N}}{\partial N}=\frac{p_{0}}{N^{2}}>0 \\
& \frac{\partial^{2} d_{N}}{\partial N^{2}}=-\frac{2 p_{0}}{N^{3}}<0
\end{aligned}
$$

Inequation (2) imposes a positive slope to curve $B$, while (2) and (3) entail together a decreasing positive slope. ${ }^{5,6}$

\footnotetext{
5 The argument we have just made about the cost-sharing benefit from user pooling assumes that all consumers equally share the provision cost. This supposition renders the exposition simpler without compromising any substance. Curve $B$ can encompass any other cost-sharing agreement provided the individual tax introduces no efficiency loss. We will explicitly address distortionary finance in Section 9 below.

${ }^{6}$ Our analysis up to this point is rigorous in the case of a good with no rivalry at all in consumption. If joint consumption somehow makes individual enjoyment smaller that the total output (due to congestion, for instance), the welfare gains from consumer consolidation are smaller than what is depicted by curve $B$ in Figure 2. We will come back to this case in Subsection 7.2 below.
} 
In deriving curve $B$, we have assumed that each consumer gets precisely her bliss quantity in return for her contribution. Referring back to Figure 1, this means every consumer enjoys quantity $g_{N}$ after paying $p_{N}$ per unit. However, and in general, when we cluster two individuals with different demands and force them to choose the output level to consume jointly at price $p_{2}=p_{0} / 2$, inevitably the selected quantity cannot be the most preferred at price $p_{2}$ for both consumers simultaneously. There is, therefore, a welfare loss associated to joining consumers and this loss corresponds to the decrease in aggregate consumer's surplus entailed by a non-bliss consumption level. Figure 3 makes this loss clear. For two consumers, let the individual charge be $p_{2}$ per unit. The bliss quantity of individual $j$ is $g_{2}$. However, suppose that the bargaining for joint consumption determines an actual output of $\tilde{g}_{2}{ }^{7}$ The shaded triangular area below the demand curve gives the decrease in consumer $j$ 's surplus imposed by the deviation from the bliss point $A$. An utility loss would also occur should the actual consumption exceed the bliss quantity. Take the case of actual $\tilde{\widetilde{g}}_{2}$ units: at price $p_{2}$, the consumer's surplus decrease associated to the deviation from the bliss point $A$ is represented by the gridded triangular area above the demand curve $D_{j}$.

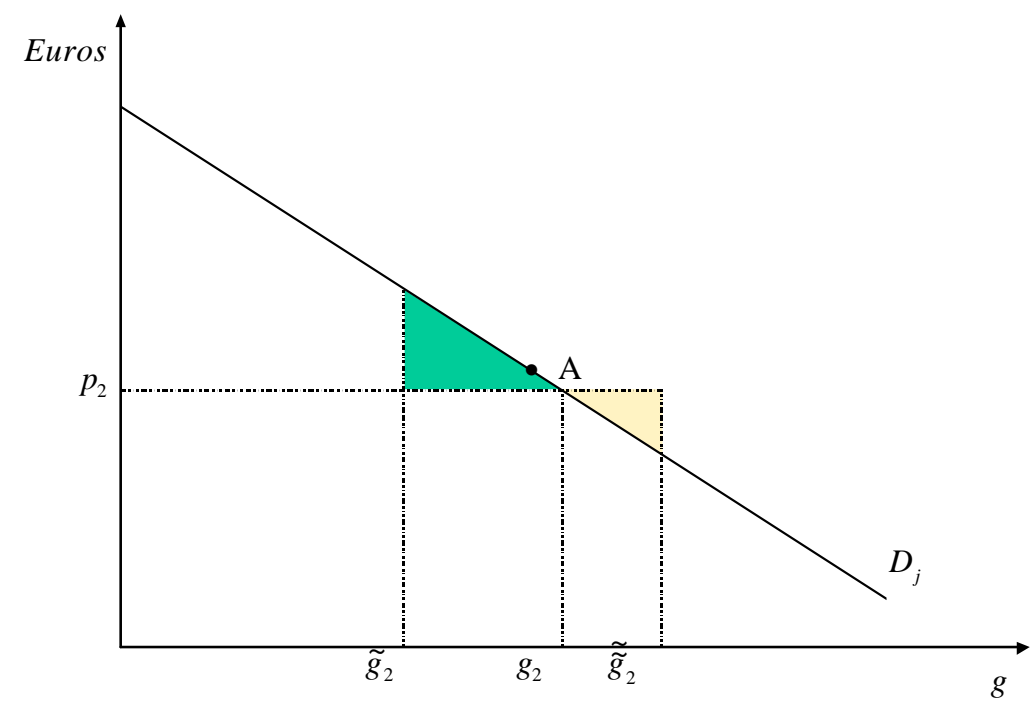

Figure 3-Individual cost from off-bliss provision

\footnotetext{
${ }^{7}$ We do not care about the specific mechanism used to make this collective decision. Whether people vote and how they vote for bliss terms is an upstream issue; here, we are just concerned with the outcome of the collective decision mechanism, whatever it may be.
} 
We should expect these utility losses to increase with the number of joint consumers. The more negotiators are in a club, the less power each has to influence the final choice. Moreover, the final choice tends to deviate more from bliss quantities the more heterogeneous are the participating consumers. So, for both reasons, it is natural to assume that the above triangular areas increase with $N$.

As before, we can aggregate utility changes. By summing up the losses in individual consumer's surplus, across all individuals, we derive a measure of the social cost associated to consolidation of consumers. Such welfare cost is depicted by curve $C$ in Figure 4. Naturally, this cost is nil when only one consumer gets the delivered output because, in this case, she consumes exactly what she most wants at the prevailing priceas is always the case with a private good. However, as explained above, the social cost increases with the size of consolidation, thus leading to a positive slope. If the dissatisfaction with actual output within a large group is higher than within a small group, then the slope of curve $C$ increases with $N$, as displayed in Figure 4-this is quite natural given the smaller individual bargaining power and wider demand diversity within larger groups..$^{8}$

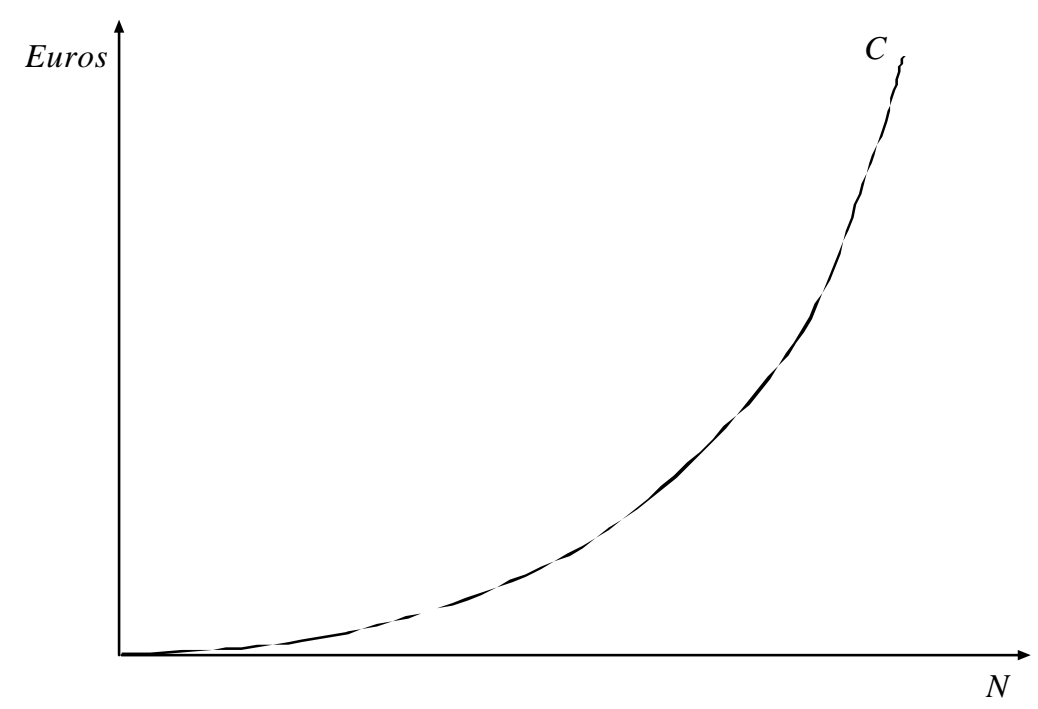

Figure 4-The basic social cost from consumer consolidation

Note that the dissatisfaction cost curve ( $C$-curve) represents precisely the motivation for jurisdictional fragmentation underlying the decentralisation theorem-Oates (1972), p. 35. Such motivation is the spatial heterogeneity in demand. Indeed, it is this variety that leads to off-bliss provisions. If individual demands were all the same

\footnotetext{
${ }^{8}$ The strict convexity is not crucial; a linear $C$-curve would be enough in the sequel.
} 
nationwide, everybody should be consuming on their own demand curves and so the provision would please everyone.

\section{Optimal-Sized Government: the Basic Case}

A number of assumptions are convenient to introduce at this stage. First, suppose there is a constant and geographically immobile population in the country. Second, there are no costs associated to collective decision-making. Third, the financing method selected to cover the provision cost does not engender any efficiency loss in the economy. We will dispense with these quite extreme hypotheses later on but, for the moment, they are useful to stress the major message of this paper. The reader will notice that these assumptions are embodied in the decentralisation theorem.

Under this framework, and given the social benefit and the social cost identified in the previous section, we can determine the welfare-maximising number of consumers of a particular public good. This first result is formalised in Proposition 1.

Proposition 1-The optimal government size: The socially optimal government size to provide a given public good is the number of consumers $\left(N^{*}\right)$ that maximises social welfare from consumer consolidation.

Proof: See Figure 5 and accompanying text.



Figure 5-Optimal government size for a particular public good

In geometric terms, the social welfare from consumer consolidation is the vertical distance between curves $B$ and $C$. This distance is maximal for population size $N^{*}$. Figure 5 makes very clear the trade-off inherent to any collective consumption. On the one hand, 
merging consumers allows for cost sharing for everyone and this obviously boosts social welfare. On the other hand, the larger the group of consumers is, the more the actual provision terms (price and quantity) deviate from the individual bliss terms and so the lower the social welfare becomes. From a social perspective, the provision terms for this good should be decided within the group of $N^{*}$ consumers. As there is a correspondence between group size and geographic areas (given population immobility), we are simply stating that the optimal jurisdiction to provide this collective good is a territory with $N^{*}$ residents. This is the socially tailored government size to deal with the good provision.

We can even add that the group size $N^{*}$ is Pareto efficient. This is done in the following proposition.

Proposition 2-Efficiency and optimal size of government: The welfare-maximising government size is Pareto-efficient.

Proof: The social welfare $(W)$ is a function of individual utilities, $W=W \mathbf{u}_{1}, \ldots, u_{N}$ ! with $\partial W / \partial u_{j}>0$. Let $N^{*}=\arg \max W$. Suppose $N^{*}$ is not efficient. Then, there exists a community size $\hat{N}$ for which at least one individual is better off and no one else is worse off. Therefore, $W\left(\hat{N} \overline{\mathbf{I}}>W\left(N^{*} \mathbf{|}\right.\right.$ by monotonicity of $W \mathbf{C} \mathbf{I}$, which simply means $N^{*}$ does not maximise social welfare-a contradiction.

So a welfare-maximising community size is Pareto efficient. Any addition or subtraction (of consumers) to this number is not a Pareto movement because at least one individual becomes worse off. This is why social welfare decreases. Note that we have been using an additive social welfare function in this paper, ${ }^{9}$ which is simply a particular case of $W=W \mathbf{k}_{1}, \ldots, u_{N}$ ! The social welfare from consolidation underlying Figure 5 sums these individual utilities across all individuals. Thus, when this sum decreases after the addition or subtraction of one consumer, it is sure that at least someone within the involved group becomes worse off, thus rendering the move inefficient.

Naturally, other public goods have different patterns of benefit and cost. Figure 6 displays three other examples.

${ }^{9} W=\sum_{j=1}^{N} u_{j}$. 




Panel (i): severe demand heterogeneity

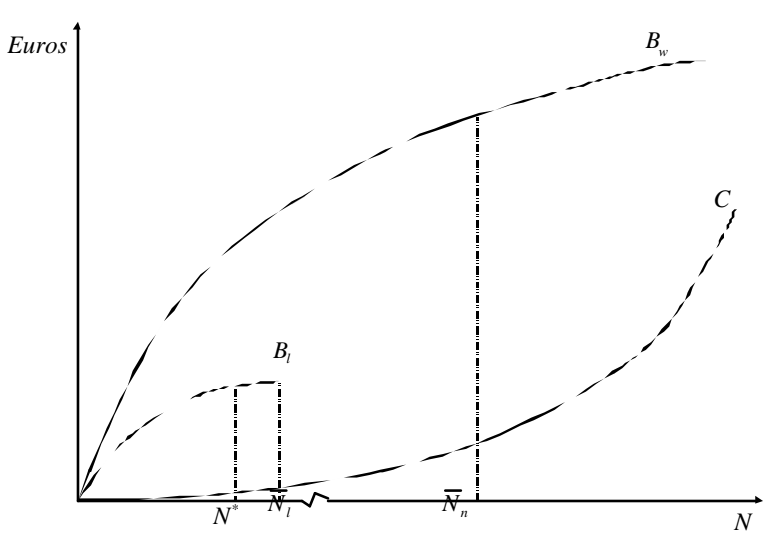

Panel (ii): global versus local public good

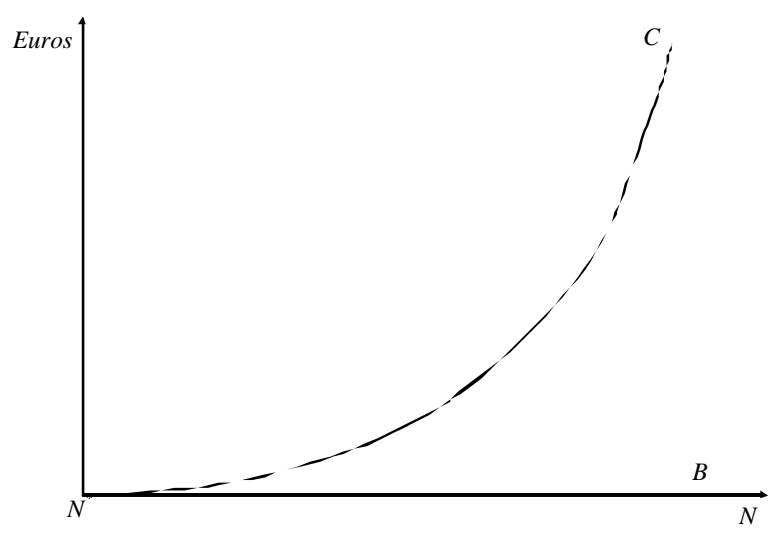

Panel (iii): pure private good

Figure 6-Optimal government sizes for different public goods

For the good in Panel (i), the cost from consolidation increases sharply after a relatively small group is attained; social welfare is maximal at government size $N^{*}$. This cost pattern is predictable, for example, in the presence of considerable demand heterogeneity. Remember the decentralisation theorem stresses precisely the spatial diversity in demand to legitimate fiscal decentralisation. If, on the contrary, all individual demands were alike, everyone would be consuming at their bliss point and the social cost from consolidation would be nil for all $N$. The optimal government size to provide such good would correspond to the maximal social benefit—case not shown.

For a worldwide public good (anti-drug fight, for instance), the benefits curve extends well beyond the total population in the country, $\bar{N}_{n}$. As shown in Panel (ii) by curve $B_{w}$, it is always possible to find additional individuals within the country willing to join the pool as all benefit from the good provision. By construction, the optimal jurisdiction size corresponds to the national population $\bar{N}_{n}$ but it would not be difficult to conceive less severe dissatisfaction costs calling for supra-national governments. By contrast, a local public good benefits only a subset of the national population. After this threshold, say $\bar{N}_{l}$, is attained, no one else is drawable towards the pool. Curve $B$ would 
thus be truncated at $\bar{N}_{l}$ in this case as is represented by schedule $B_{l}$ in Panel (ii). The optimal-sized jurisdiction counts $N^{*}$ individuals and is thus a subset of the nation. The local public good should therefore be provided out of several governments each sized $N^{*}$.

Finally, take the case of a purely private good. The cost from consolidation is as usual: having the individual consumption level decided collectively engenders off-bliss dissatisfaction for every group member. The contrast lies with social benefit. In fact, adding-up consumers does not affect the terms of trade offered to any individual within the group. Referring back to Figure 1, consumer $j$ does not face any price reduction or quantity increase when other participants are joined. This is so because further members will not consume the very same units enjoyed by individual $j$. Each additional consumer requires additional output units to be provided, as there is rivalry in consumption. Therefore, for a constant marginal cost, the price charged to $j$ remains $p_{0}$ no matter how many individuals consume the good. In terms of social welfare from consolidation, this translates to a $B$ curve coincident with the horizontal axis, as shown in Panel (iii). Obviously, this represents the extreme case of fiscal decentralisation, a situation where the optimal size of government $\left(N^{*}\right)$ is the individual.

\section{The Correspondence Principle and a Federal System of Government}

In the preceding discussion, the optimal-sized group is made of people that benefit from the public good provision. More strongly, the set of beneficiaries and the set of decision-makers overlap perfectly. For a geographically fixed population, a group size translates immediately to a spatial area (jurisdiction). ${ }^{10}$ Social welfare is therefore maximal when the provision of collective goods is decided within the jurisdictions over which their benefits are defined. Wallace Oates has termed this situation as one of perfect correspondence between the government's jurisdiction and the number of individuals who benefit from the government's decision-making. In his own words, “(...) under such a perfect correspondence, each government unit provides that level of consumption that equates at the margin the sum of the benefits and costs to its constituency.",11

As the previous section made clear, the benefits and costs of government consolidation depend upon the public good at stake. Each collective good calls for a

\footnotetext{
${ }^{10}$ Hence, when we say a collection of individuals decides the provision terms of a collective good, we are simply stating their jurisdiction over the spatial area where they reside.

${ }^{11}$ Oates (1972), p. 48.
} 
specific government size to decide on its provision terms. At one extreme, there are goods whose optimal jurisdiction is quite small, requesting many similar-sized government units around the country. At the other extreme, we may find goods that are best handled by a single, large government with jurisdiction over all consumers-in the country, the European Union or other supra-national spaces. A whole spectrum of multiple intermediate-sized governments fills in the gap between these two polar cases.

Therefore, the correspondence principle we have been elaborating points for a federal system of government, that is, a governmental architecture where the jurisdiction of each unit matches exactly the group of consumers benefiting from the collective good it provides.

The case of perfect correspondence is embodied in the decentralisation theorem. In fact, its hypotheses are the assumptions we have been using so far. However, as explained in Baleiras (2001), Sc. 5.2, there are reasons to cast doubt on their plausibility. In what follows, we are going to remove these assumptions one by one and see how the endogenous government size changes. At the end, we will reassess the correspondence principle and the vindication of a federal governmental architecture.

\section{Scale Economies}

Let us first remove the assumption of a constant marginal provision cost. Many services typically provided by governments are subject to increasing returns to scale at least over a relevant range.

In Figure 1, the adding-up of consumers allowed for cost sharing among the group members: reduction in individual prices from $p_{0}$ to $p_{N}$. Note however that augmenting the club size does not allow for scale economies exploitation and the concomitant cost reduction. Implicit in all our discussion has been the non-rivalry in consumption nature of the collective good. In fact, we have assumed throughout the domains of curves $B$ and $C$ that everyone is consuming the very same quantity. So, the consolidation of consumers does not lead to any output expansion and so no scale economies are actually ripped off. Therefore, the mere existence of scale economies in the technology does not mean automatically that society may profit from them. The way people co-consume the good matters also. 
In fact, one case where scale economies make a difference happens when the good is subject to some degree of congestion or rivalry in consumption-mixed good. ${ }^{12}$ In this case, further individuals will only be willing to pay for the provision if its output increases. Yet, there is another case where scale economies can be enjoyed and non-rivalry prevails: the local public good case. Here, there is non-rivalry within the jurisdictional units but the provision benefits stop at the borders. Still, when two or more jurisdictions merge to provide the good jointly, scale economies become feasible. We will assess the two cases in what follows.

\subsection{The mixed good case}

Take a collective good subject to some rivalry in consumption and scale economies in provision over the relevant range. The following result holds.

Proposition 3-Scale economies and optimal government size in the case of a mixed good: If the provision of a mixed good is subject to scale economies, the welfaremaximising government size is larger than when the marginal provision cost is constant over the relevant output range.

Proof: see Figures 7-8 below and the accompanying text.



Figure 7-Change in consumer's surplus due to scale economies

As the output expands to accommodate a larger pool of consumers, the marginal cost drops. Recovering our previous notation, let $p_{0}$ be the marginal cost corresponding to

\footnotetext{
${ }^{12}$ A mixed good is an intermediate case between a public and a private good-rivalry is neither nil nor full.
} 
a single consumer. The marginal cost with $N$ consumers is $p_{0}^{\prime}, p_{0}^{\prime}<p_{0}$ reflecting the cost reduction. Hence, the relevant price charged to each of the $N$ consumers is now $p_{N}^{\prime}$ in Figure 7 , where $p_{N}^{\prime}=p_{0}^{\prime} / N$.

The gridded trapezoidal area measures the individual benefit from scale economies. It adds to the previous utility gain (shaded trapezoidal area) associated to cost sharing and identified before in Figure 1. Aggregating over all consumers, we derive a larger social benefit from consolidation, as displayed in Figure 8 below. Curve $B$ rotates upwards to position $B^{\prime}$ reflecting larger gains in consumer's surpluses.

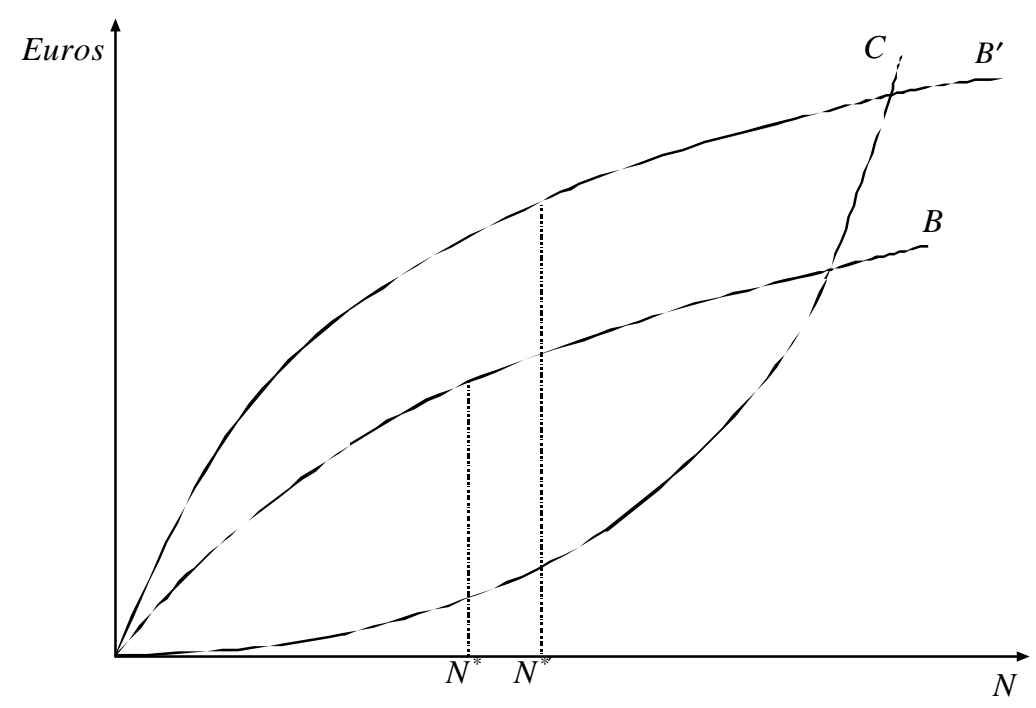

Figure 8- Scale economies and the optimal government size

For a given social cost schedule, the optimal government size increases to $N^{* \prime}$. Note that the correspondence principle still means a perfect correspondence between the government size and the number of people benefiting from the good it provides. This is no longer true in the case below of merged jurisdictions and local public goods.

\subsection{The local public good case}

For immobile population, a quantity of consumers corresponds to a territory size. The local public good, by definition, benefits people residing within a given territory or geographic space only. The benefits stop at the jurisdiction's edge- nobody benefits from the provision beyond this threshold distance. Contrary to a mixed good, in this case there is no rivalry at all in consumption within the jurisdiction where the good is provided. Hence, the consolidation of consumers up to the threshold distance involves no output expansion and so no marginal cost reduction. 
Nevertheless, if several jurisdictions decide to merge and form a single government to provide the good to the various consumer groups, the operational scale necessarily expands-there is rivalry between the former jurisdictions. Therefore, scale economies become available to all consolidated consumers and the following outcome arises.

Proposition 4-Scale economies and the optimally-sized governemnt in the case of a local public good: If the provision of a local public good is subject to scale economies, and jurisdictions merge into a single government, then the welfare-maximising government size is larger than when the marginal provision cost is constant over the relevant range.

Proof: Figures 7-8 apply again. The optimal group size is necessarily bigger $\left(N^{*^{\prime}}\right.$ instead of $N^{*}$ ), reflecting the consolidation of jurisdictions explained before.

The joint provision by the single, after-merge government corresponds to the typical provision by a central government. In this case, and contrary to the mixed good one, the correspondence principle no longer reads as perfect overlapping between the government size and the group of provision beneficiaries. Now, the enlarged jurisdiction is made of several groups, which means that the other groups influence the output provision for one particular group - the government's jurisdiction no longer corresponds perfectly to the geographic area of benefit (of each local public good).

Having stated that, we must however acknowledge that the imperfect correspondence just derived is not inescapable in the case of a local public good. It is inevitable only when the isolated jurisdictions decide to merge and set a single government. However, a horizontal co-operation may secure the scale economies while keeping the perfect correspondence.

Proposition 5-Scale economies and optimal coalition of independent governments in the case of a local public good: If the provision of a local public good is subject to scale economies, public procurement by a coalition of independent jurisdictions improves welfare.

Proof: We just need to reinterpret the variables. Let $N^{*}$ represent the size of each independent jurisdiction and $N^{* \prime}$ the optimal size of the coalition. From Figure 8 and the maximum definition, total welfare is higher with $N^{* \prime}$ than with $N^{*}$.

Proposition 5 thus refers to a set-up where local governments keep their sovereignty but co-operate in a joint procurement programme. This scenario looks plausible when the production and provision activities are separated and scale economies lie with the former alone. Under these circumstances, a common procurement agreement among the concerned jurisdictions may well secure the same cost advantages for everyone as an order placed by 
a consolidated, single government. Such agreement may even allow for some discretion in provision terms across the participating jurisdictions. Hence, each government's jurisdiction continues to overlap perfectly the geographic area of provision benefit.

\section{$6 \quad$ Interjurisdictional Spillovers}

If the provision of a collective good by one group of consumers ${ }^{13}$ spills over into the utility of another group, then the curves $B$ and $C$ no longer fully reflect the social welfare associated to that provision. This is true whether the provision benefits or harms external consumers. Without the internalisation of this external effect, those people who decide the output level do not represent all relevant consumers-again, a case of imperfect correspondence.

In general, the smaller the group within which the provision is decided, the more the external effects are disregarded. To put it another way, when an external individual enters the club, her interests are no longer external to the club-they get internalised. Hence, this consolidation entails a welfare gain. So, the larger the group, the more the external effects get internalised and the more social benefits increase. This is representable by an upward rotation of the benefits curve to position $B^{\prime}$ in Figure 9.

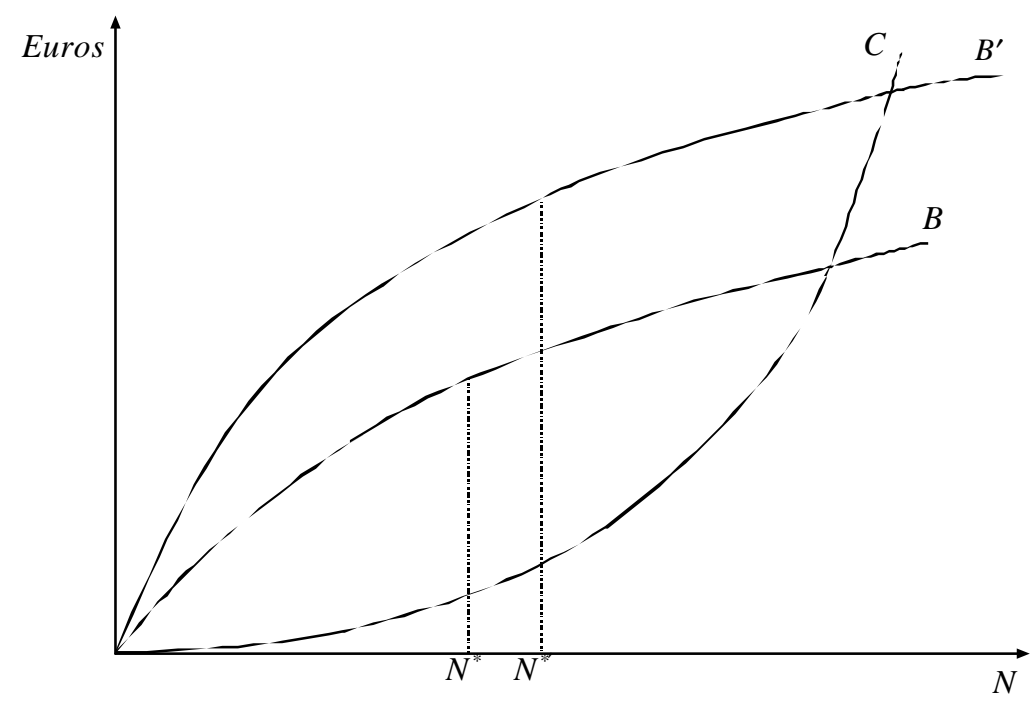

Figure 9-Interjurisdictional spillovers and the optimal government size

\footnotetext{
13 A group of consumers corresponds to a jurisdiction, given population immobility and the concomitant correspondence between collections of individuals and geographic areas or territory sizes.
} 
The height between schedules $B$ and $B^{\prime}$ measures the social gain associated to the internalisation of the externality and pushes towards larger jurisdictions. Such consolidation however exacerbates the loss from off-bliss consumptions. Proposition 6 states the resultant trade-off.

Proposition 6-Interjurisdictional spillovers and the optimal government size: If the provision of a public good spills over benefits or costs to external residents, and these effects are taken into consideration by the provision decision, the welfare-maximising government size is larger than when the external effects are disregarded.

Proof: See the Appendix for a proof of the upward rotation of the $B$-curve in Figure 9. For a linear or strictly convex dissatisfaction cost curve ( $C$-curve in Figure 9$)$, the result is immediate: $N^{* \prime}>N^{*}$.

So, in light of spatial externalities, efficiency calls for a larger club size, a move towards greater centralisation. The perfect correspondence between a government's jurisdiction and benefit areas is preserved once consumers merge to internalise spillovers. This is no longer true with exogenous borders and co-operative decentralisation. In this case, the jurisdiction that causes the externality does not contain all consumers of the public good. The external beneficiaries reside outside that jurisdiction and so the correspondence between government size and geographic area of consumption becomes imperfect.

\section{Geographic Mobility of Population}

We have already noted that if individual demands were all alike across the country the costs from consolidation would be nil and the socially optimal jurisdiction would be the entire nation-full centralisation would then provide the efficient output level. It is our purpose in this section to stress that the gains from decentralisation depend both on the degree of demand heterogeneity in the country as a whole and on the degree of demand heterogeneity within the jurisdictions that decide output provision. To make this point clear, and to begin with, suppose that the two degrees are the same, i.e. the heterogeneity within geographically separated groups of consumers is the same as in the nation as a whole. Then the $C$-curve is an upward-sloping line, like in Figure 10. Adding one resident to a group of 10,000 individuals increases collective dissatisfaction with the provision terms as much as when one further resident is appended to a group of 100,000 people - this explains the linearity of curve $C$. 




Figure 10-Voting with feet and the optimal government size

By contrast, imagine that people are distributed in space such that the diversity in individual demands is higher in the country as a whole than within each collection of residents — each jurisdiction. This would be the case if the new residents added first to each group were those with demands closer to the original residents. Under these circumstances, as $N$ expands the marginal cost from consolidation increases too, leading to a total cost curve as $C^{\prime}$ in Figure 10. Within smaller groups, individual demands are now much similar and so the individual welfare losses from off-bliss consumptions (the triangular areas in Figure 3, p. 6) get reduced. As the group size expands to integrate more diverse individuals, these losses increase. These changes in consumers' surplus explain why curve $C^{\prime}$ passes below curve $C$ for small groups and above it for large groups.

It is now clear why the decentralisation net gains are enhanced once people cluster as described in the previous paragraph, i.e. such that the demand heterogeneity within jurisdictions gets smaller than in the country as a whole. For small groups $(N<\tilde{N})$, welfare increases by the vertical distance between curves $C^{\prime}$ and $C$.

\subsection{Voting with feet}

Why does all this discussion matter for the analysis of mobility? It matters to the extent that mobility is one way people have to countervail their dissatisfaction with the provision terms they are receiving in their current jurisdictions. If someone feels powerless to influence the collective decision-making according to her preferences, she can always vote with her feet, that is, moving away to another jurisdiction where better terms are offered. Inasmuch as people behave in this way, we should expect smaller demand variety within groups and greater demand diversity in the country as a whole. The more mobile people are, the more convex becomes the dissatisfaction curve. For example, in Figure 10 
curve $C^{\prime \prime}$ portrays higher mobility than curve $C^{\prime}$. Mobility thus pressures towards larger jurisdictions $\left(N^{* \prime \prime}>N^{* \prime}\right)$.

Actually, Charles Tiebout first predicted this behaviour of consumer-voters in his classic paper Tiebout (1956). Households observe the particular expenditure-revenue package offered by each jurisdiction and take them into consideration when deciding where to locate. Inasmuch as people are sensitive to local fiscal deals, we should indeed expect them to cluster according to preferences. Demand heterogeneity would then tend to be smaller within rather than between jurisdictions.

So spatial mobility cuts the social losses from consolidation and this leads to somewhat larger optimal jurisdictions. However, mobility may also affect the social benefits from consolidation. This is certainly the case when the good is subject to some degree of congestion and the exclusion of consumers is unfeasible. Take the example of a swimming pool. It is true that group members benefit from the inclusion of additional partners through reduced cost shares. However, after a certain size, the facility becomes crowded, and each member finds not enough space to swim at ease. ${ }^{14}$

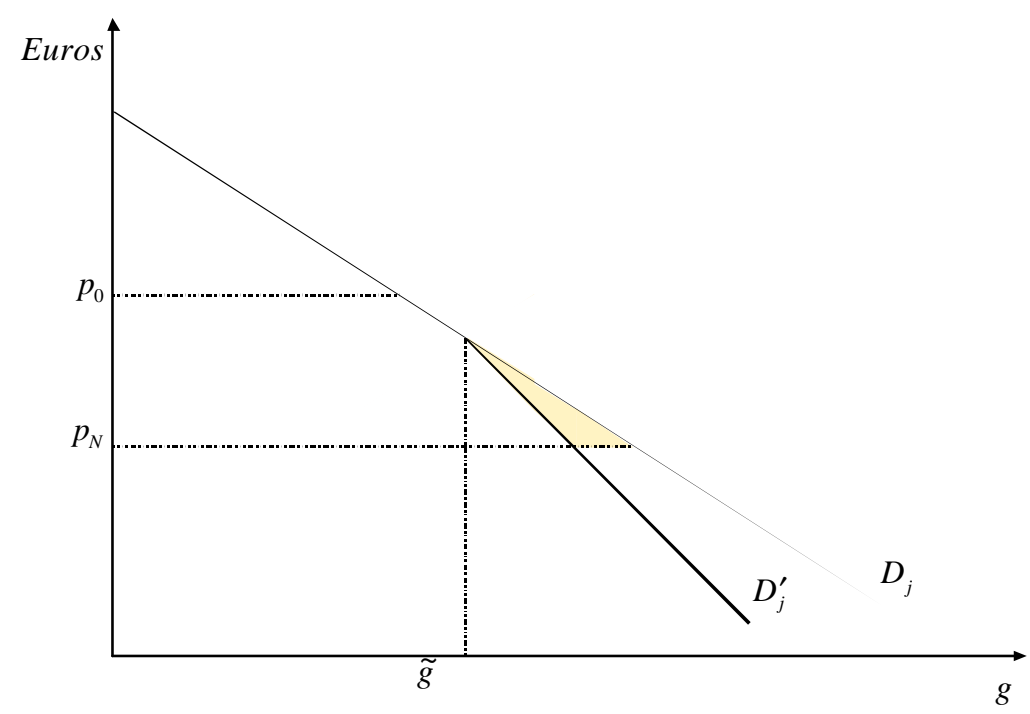

Figure 11-The individual congestion cost of mobility

\footnotetext{
14 The swimming pool is a famous example of a congestionable collective good after the seminal paper by James Buchanan-Buchanan (1965). This article lays down the foundations for an economic theory of clubs and uses the swimming pool to illustrate the reasoning.
} 
Technically speaking, the individual marginal benefit decreases after that size is reached. Geometrically, this means the individual demand curve shifts downward when the facility becomes crowded-output level $\widetilde{g}$ in Figure 11. The gain in consumer's surplus due to consolidation is now smaller, being reduced by the amount of the gridded area.

In aggregate, this entails a downward rotation of the benefits curve in Figure 12, at least after a threshold size $\tilde{N}$ is attained. Hence, to the extent congestion costs are plausible, the optimal government size is reduced. In the real world there are not many public goods truly with no rivalry at all in consumption. Most exhibit some crowding effects after a while. Thus, talking about mobility-induced congestion is not mere rhetoric. Whereas a private club can bar the admission of new members at any time and so control for the congestion, the same is unlikely in a public club, a jurisdiction. In fact, contrary to a private club, jurisdictions are normally open clubs. This is so because it is not politically right to fence a territory and deny further immigration. ${ }^{15}$

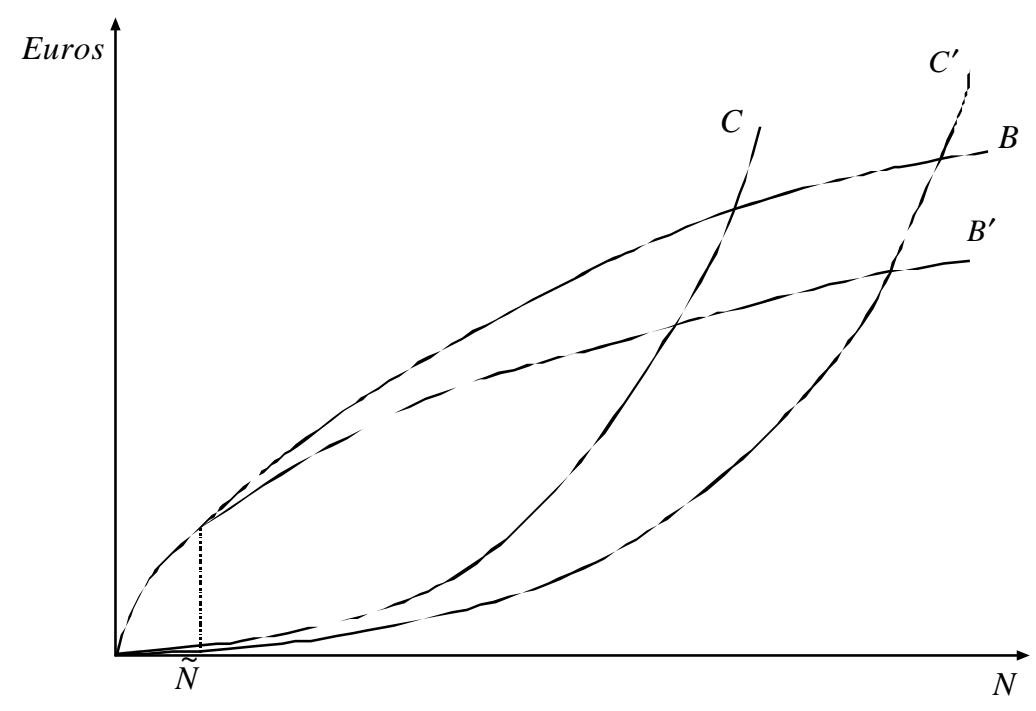

Figure 12-Spatial mobility and the welfare from consolidation

We can go back to Figure 12 for a summary. Household mobility exerts a contradictory influence upon the optimal government size. The more we believe people

\footnotetext{
15 In practice, however, there are a few subtle ways to exclude consumers and so to limit the congestion damages. Zoning regulations at the local level are one such mean. For example, when the local government imposes a minimum land consumption per household in a particular neighbourhood, it raises the price of land and housing in that location. This obviously excludes the poorest families. At a national scale, we can also find examples of consumers' exclusion. The European Union is very attractive to East-European workers at the turn of the millennium. Faced with an ageing population, EU governments realise the output benefits of a larger working force. However, a massive immigration may lead to xenophobic feelings by the natives, which looks like some sort of congestion cost. This explains why labour movements between EU and Eastern Europe are not free.
} 
chose their location according to local fiscal proposals, the larger are the net gains from decentralisation. The more crowded becomes the consumption of the collective good, the less bright emerge the merits of decentralisation. Again, the optimal government size is a case study, as the following proposition puts forward.

Proposition 7-Spatial mobility and the optimal government size: Household mobility across space induces an ambiguous impact upon the welfare-maximising government size.

Proof: Spatial mobility leads to two contradictory effects. On the one hand, voting with feet choices reduce the marginal cost from consolidation for all $N$, thus calling for a larger optimal size. On the other hand, a larger size potentialises facility crowding, which reduces the marginal benefit from consolidation and calls for a smaller optimal size. The ultimate impact on optimal $N$ is qualitatively ambiguous.

\section{Costs of Governance}

Up until now, we have ignored the specific costs associated to collective decisionmaking. This is not realistic. Once people cluster to consume jointly, they need to build up and maintain an institutional set-up where the decisions about provision terms are made. From a single-person committee serving as agent for a one hundred people assembly to a complex structure of public agencies managed by professional staff and chaired by officials elected by one billion people, a whole array of institutional set-ups is foreseeable.

Let us coin the "governance costs" label to name the costs of implementing and keeping in force the institutional set-up. Without the organisation, no collective decisions are made and therefore no public provision of goods will ever occur. So the governance costs refer to the costs of collective decision-making. We can think of three kinds of governance costs: operational costs, entropy costs and rent-seeking costs.

\subsection{Operational costs}

Operational costs include the salaries of staff and elected officials, office space and equipment rentals, other office input expenditures, the cost of holding elections, referenda and other media to hearing people's voice, etc. In a word, operational costs refer to the direct costs of government. They are essentially fixed costs-once a government unit is set up, they emerge. The smaller is the scale of provision, the larger is the number of government units required to dispense the good nationwide and so the higher these operational costs (OC) are. Curve $O C$ in Figure 13 illustrates the path of operational costs as a function of the jurisdiction size. The declining pattern reflects the fact that these costs 
are basically expenditure in fixed inputs, more or less proportional to the number of governments providing the good in the country.

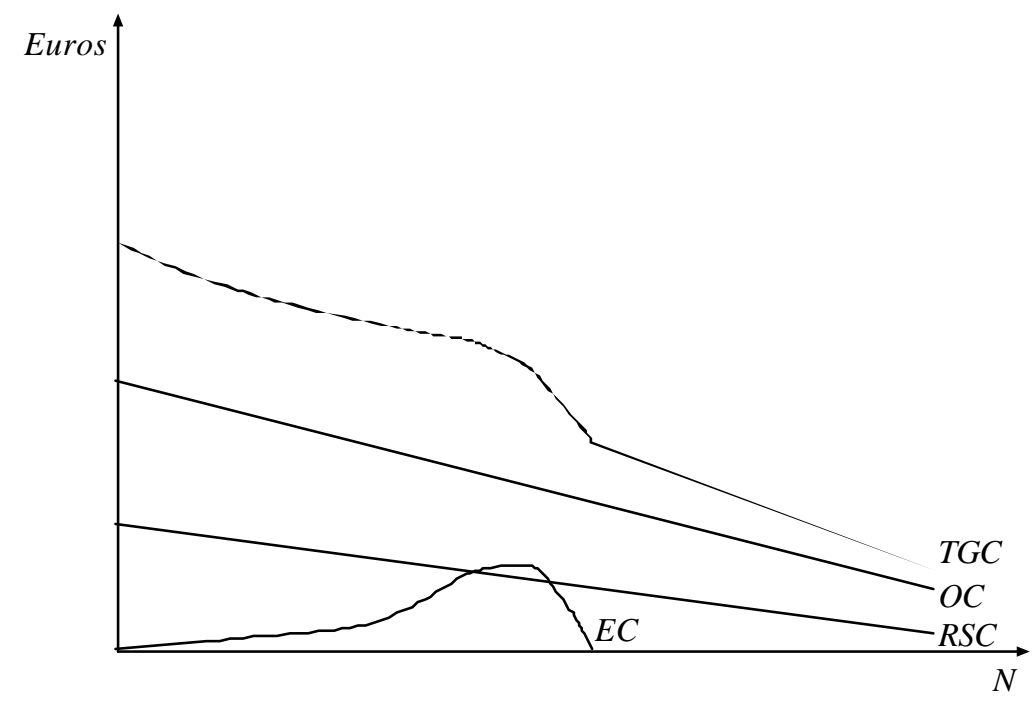

Figure 13-The governance costs

\subsection{Entropy costs}

In a federal system of government, the several decision-making units have to talk and negotiate a number of issues. One possible hot topic is the share of tax bases. Should a particular tax base, say personal income, be assigned to the central government or to a myriad of small government units? Let the discussion of such topic be open and the controversy will be endless. In general, subnational governments are likely to react to every central decision with non-uniform spatial repercussions. With losing and winning communities, the subnational governments will get involved in disputes among themselves and with the central government. The fewer the subnational units are, the larger each one is and so the stronger its bargaining power will be. This potentialises confliction, more entropy within the general government. More entropy renders collective decision-making more expensive. Curve EC in Figure 13 illustrates the shape of entropy costs. These costs are relatively insignificant when the good is provided out of many small, local government units with virtually no individual bargaining power. As the provision scale expands, and the number of political players diminishes, the entropy is likely to rise within the general government. After reaching a peak with just a few, powerful regional governments, it declines to zero, when the provision is fully centralised. With a sound economic constitution, where rules prevail over discretion in policy-making involving spatial repercussions, these costs can be substantially contained. 
Finally, there are rent-seeking costs to care about. Often, the costs of a policy decision are not distributed by individuals the same way as benefits are. When the latter are concentrated on just a few and the costs are borne by many others, we should expect lobbying activities by the few beneficiaries in favour of a larger provision. Public subsidies to a particular industry illustrate the argument. To the extent that the final outcome fails to match social benefits with social costs, lobbying creates inefficiency in the economy. This welfare loss is felt within the community where lobbying acts but it may harm other jurisdictions as well, thus imposing an even more severe welfare loss. Take the case where lobbying is more successful in some jurisdictions than in others; then, we may well expect interregional price differences without an efficiency support. These distortions are obviously a welfare loss we must account for when assessing governance costs.

In principle, the smaller a government unit is, the more vulnerable to lobbying it becomes. Again, this is a matter of relative bargaining power, now between a public authority and a private body. The stronger the latter is vis-à-vis the former, the more rents it expects to extract from approaching the government. ${ }^{16}$ Hence, the rent-seeking costs of governance tend to evolve with government size as displayed by curve $R S C$ in Figure 13: high with small-size governments (because the number of weak governments is large), low with large-size governments (small number of stronger governments). This pattern reflects two things: first, the decline in likelihood of lobbying activities as $N$ increases, which was referred above; ${ }^{17}$ second, the decline of the inefficiency size compared to a measure of the community's economy. ${ }^{18}$ Note that we are not referring to lobbying activities in general. We are solely speaking about the rent-seeking activity addressed to the public good provision under discussion.

\footnotetext{
16 There is a vast literature on rent seeking that has motivated these ideas about governance costs. Tullock (1967) and Krueger (1974) are founding theoretical contributions. Interesting recent applications to multilevel governance include Baumgardner (1993), Renaud and van Winden (1991) and Dougan and Kenyon (1988). Interestingly, the work by Bardhan and Mookherjee (1999) addresses the relative vulnerability of local and central governments to pressure groups.

${ }^{17}$ It costs more to bribe or otherwise influence the decision of a large rather than a small government, ceteris paribus; thus, the quantity demanded diminishes as $N$ increases.

${ }^{18}$ A subsidy to one entrepreneur in a community of one thousand people may generate a larger loss in per capita real income than all lobbying outcomes at the national scale.
} 
By adding up the three cost components, we can finally derive the total governance costs (TGC) as a function of government size. They are represented by curve TGC in Figure 13. ${ }^{19}$ Summing these costs to our already familiar dissatisfaction cost (curve $C$ ), we derive the total costs from consolidation as curve $C^{\prime}$ in Figure 14.

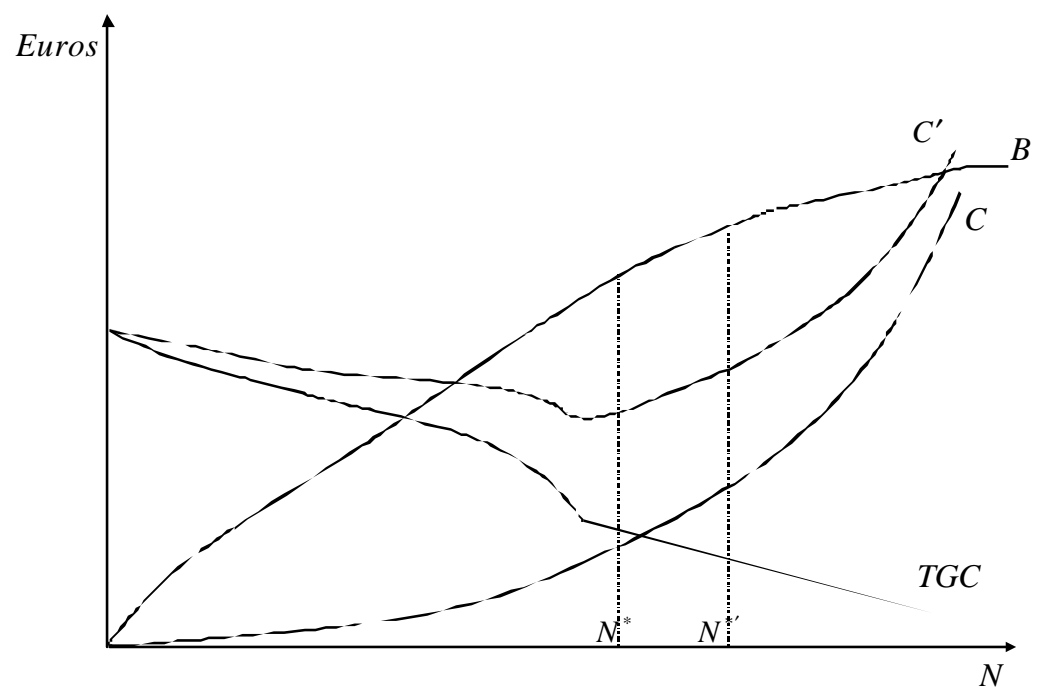

Figure 14-Governance costs and the optimal government size

Once governance costs are taken into scrutiny, the merits of fiscal decentralisation turn pale. Note that the rise in total costs from consolidation covers the whole population but strikes stronger the smaller is the scale of government. Not surprisingly though, the optimal government size with governance costs increases, say from $N^{*}$ to $N^{*^{\prime}} \cdot{ }^{20}$ Proposition 8 makes this clear.

Proposition 8-Governance costs and the optimal government size: with downwardsloping total governance costs, the welfare-maximising government size is larger than when no such costs exist.

Proof: Figure 15 helps to establish the result. Negative marginal governance costs ( $d T G C / d N$, curve not displayed) places the total marginal cost curve $(d C / d N+d T G C / d N)$ definitely below the original marginal cost from consolidation curve $(d C / d N)$ for all $N$.

\footnotetext{
${ }^{19}$ From a qualitative viewpoint, we have no argument to decide on the precise shape of the cost component curves or their relative positions. However, this ambiguity is inconsequent for our analysis - see Proposition 8 below. An empirical study may perhaps resolve the ambiguity, at least for particular applications.

${ }^{20} N^{*^{\prime}}$ is the community size that maximises the vertical distance between curves $B$ and $C^{\prime}$ in Figure 14 .
} 
The intersection with the marginal benefit curve $(d B / d N)$ necessarily occurs at the right of the intersection between schedules $d B / d N$ and $d C / d N$.

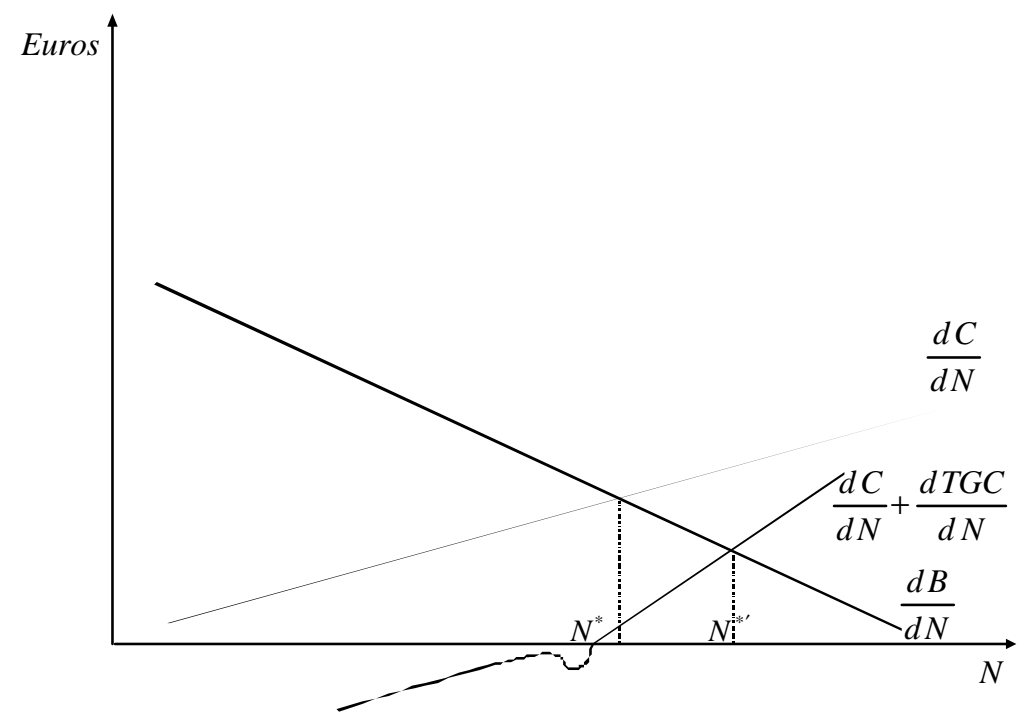

Figure 15-Optimal government size in the space of marginal benefits and costs

This result is independent of the relative position of all curves. The $T G C$ decrease with $N$, making the associated marginal cost negative over the entire domain. This suffices to establish the result.

\section{Second-Best Finance}

In computing the social gains and losses from consolidation via the changes in consumers' surplus, we have assumed the provision was paid through head taxes. Hence, there were no efficiency $\operatorname{costs}^{21}$ associated to revenue raising. What if this first-best finance is not feasible? For one reason, scale economies inhibit full funding through marginal cost pricing; if the deficit is paid out of distortionary taxation, there is a welfare loss to be accounted for. For another reason, consumers may fail to reveal their true demands for public goods if they know that individual cost shares are endogenous in the level of consumption. This is the well-known problem with Lindahl taxation, which leads to underprovision of the public good, again a welfare loss we have ignored so far. ${ }^{22}$

Whatever the reason, there are specific welfare losses to consider when second-best finance is required. Of course, the inefficiency severity will depend on the circumstances at

\footnotetext{
${ }^{21}$ Other than the dissatisfaction costs entailed by off-bliss provision terms.
} 
stake, namely the kind of revenue instrument. This is made very clear in Part III of Baleiras (2001), where we provide an extensive analysis of most revenue instruments typically available to subnational governments. Let us just consider two examples to give the flavour of what is at issue. In example 1 below, we will figure out how the efficiency costs of personal income taxation evolve with government size. A similar exercise is performed for benefit taxation in example 2 .

Example 1: personal income taxation. As we make clear in Baleiras (2001), Sc. 4.2, redistribution in presence of significant household mobility calls for substantial government consolidation. Inasmuch as a personal income tax contains redistributive elements (and virtually all actual systems do contains such elements), richer households will try to avoid their burden by moving away to cheaper tax jurisdictions. Suppose the personal income tax is administered independently by a collection of subnational governments. In order to collect a given revenue target, an individual government has to raise the tax rate high enough to compensate for the base outflow. But this attitude increases the excess burden for remaining taxpayers. So, the higher is the mobility of taxpayers across jurisdictions, the larger is the efficiency loss necessary to meet the revenue target. As mobility across many and small jurisdictions is higher than across few and large jurisdictions, the total efficiency loss of this tax decreases with $N$, the size of the government. Curve $F C_{1}$ in Figure 16 illustrates the efficiency loss path associated to example 1, where the initials "FC" stand for (social) finance costs.

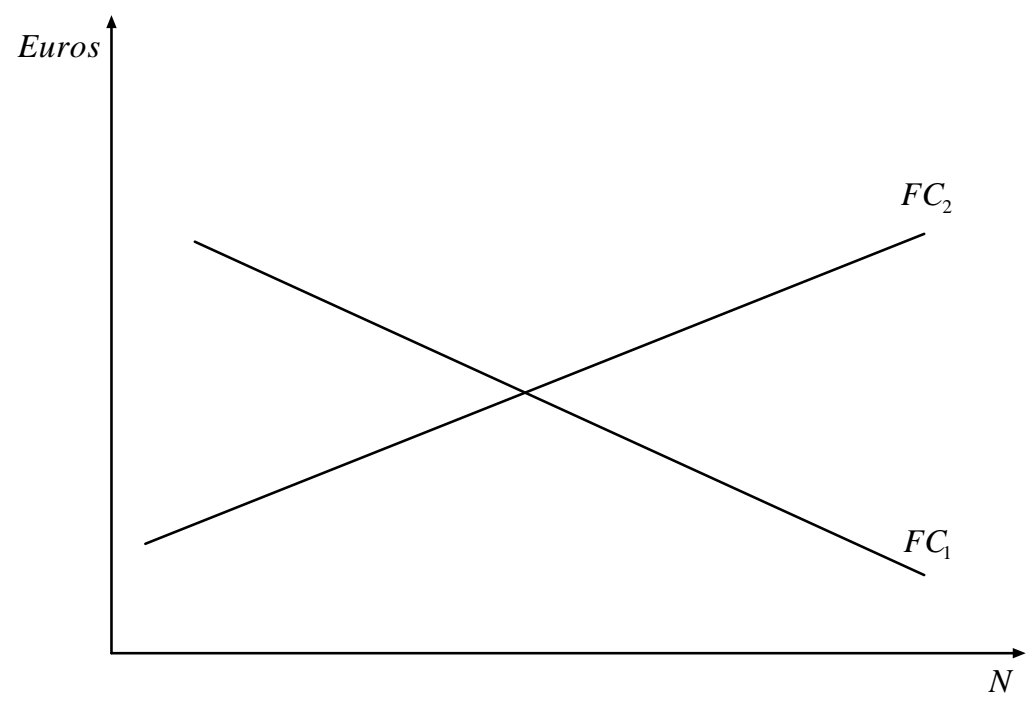

Figure 16-Examples of finance cost patterns

Footnotes, continued from previous page

${ }^{22}$ Actually, a head tax when individual demands are equal corresponds to a Lindahl tax. 
Example 2: local benefit taxation. Local governments are closer to consumers of local public goods and have an informational advantage over higher-level governments about individual willingnesses to pay and provision costs. Suppose benefit taxation is a feasible finance instrument. ${ }^{23}$ Given this information advantage, we may presume that the welfare losses associated to benefit taxation increase as the community enlarges and the number of providers reduces. Hence, the finance costs in this case increase with $\mathrm{N}$-curve $F C_{2}$ in Figure 16.

The following proposition sets the link with the optimal government structure.

Proposition 9-Second-best finance and the optimal governmnent size: The efficiency costs of second-best finance exert a qualitatively indeterminate impact upon the welfaremaximising government size.

Proof: The total costs from consolidation add up the by now familiar dissatisfaction cost $(C)$ with the relevant finance cost $(F C)$. The two examples $F C_{1}$ and $F C_{2}$ suffice to establish the indeterminacy. With the downward-sloping $F C_{1}$ curve, the marginal total costs curve shifts downward and the optimal $N$ increases. However, with the upwardsloping $F_{2}$ curve, the marginal total costs curve shifts upward and the optimal $N$ decreases, thus proving the qualitative indeterminacy.

At this level of generality, it is thus impossible to predict the ultimate impact of finance costs upon the optimal government size. However, we may expect a larger optimal size and fewer government units when these costs are declining (as $F C_{1}$ ), and smaller optimal size and more government units in the opposite case (the $F C_{2}$ example). This is so because the gains from decentralisation deteriorate in the former case and improve in the latter.

Once a government finances a local public good provision by anything but user charges and benefit taxation, the set of consumers no longer corresponds to the set of contributors. This is particularly evident in the case of intergovernmental transfers. The grant received by a local government $A$ is taxpayers' money levied all over the country. To the extent that this revenue is raised through distortionary taxation, most efficiency loss associated to second-best finance is borne by non-residents. As the subsidised good benefits $A$-residents only, we find again an imperfect correspondence between the size of

\footnotetext{
${ }^{23}$ The feasibility of benefit taxation is discussed in Baleiras (2001), Sc. 7.1.
} 
the jurisdiction where provision terms (quantity and payment) are decided and the number of individuals who benefit from the good.

\section{A Pragmatic Synthesis: System of Multifunction Governments}

The size of jurisdictions where the provision terms of individual public goods should be decided is endogenous. This endogenousness stems from a complex array of reasons. In this paper, we have thoroughly examined the driving forces of jurisdiction formation. On the one hand, factors like demand (and supply) heterogeneity, congestion and welfare losses from some kind of second-best finance call for the fragmentation of jurisdictions. On the other hand, user-pooling cost savings, scale economies, interjurisdictional spillovers, voting with feet behaviour, governance costs, and welfare losses from another kind of second-best finance pressure towards jurisdiction consolidation. Whereas the size of government corresponds exactly to the number of beneficiaries from the good it provides when only demand (and supply) heterogeneity and cost-share savings are considered, the correspondence gets increasingly imperfect once the other factors are added up to the design of governmental architecture.

Although important in practice, most of these benefits and costs from consolidation are hard to assess empirically. Moreover, their relative importance varies a lot with the good whose provision we are studying. This is why the optimal government size depends a great deal on the assigned function. A hypothetical distribution of optimal sizes for singlefunction governments is presented along the line in Figure 17. The national population sums $\bar{N}$ individuals. Good 1 calls for the smallest government size $\left(N_{1}\right)$ and the largest number of providing units across the national territory. By contrast, the optimal size to provide good 8 encompasses the total national population and a fraction of neighbouring foreigners; a single, national government should decide on its provision terms and cooperate with the neighbouring national government. The empirical difficulties with the measurement of optimal sizes may prevent the analyst from identifying exactly the right jurisdiction scale. However, sensitivity and good wisdom in the appraisal of relevant benefits and costs from consolidation will certainly help to predict whether the ideal size is closer to one extreme or the other in the line of Figure 17.

$$
\begin{array}{lllllllll}
1 & 1 & 1 & 1 & 1 & 1 & 1 & 1 & \\
N_{1} N_{2} & N_{3} & N_{4} & N_{5} & N_{6} & N_{7} & N_{8} & &
\end{array}
$$

Figure 17-Hypothetical distribution of optimal-sized single-function governments

Furthermore, we should expect to find interactions between several functions, namely in the case of governance costs. For some goods, with slightly different optimal 
government sizes, the same fixed inputs of governance capacity enable their joint provision. This is the case when there are scope economies; by reducing the total provision cost associated to a set of public goods, scope economies are a persuasive argument in favour of multifunction governments.

Given scope economies with function consolidation and the inherent uncertainty with single-function optimal size estimates, a pragmatic approach will likely recommend the formation of multifunction governments. Applying pragmatism to the hypothetical distribution in Figure 17, one would perhaps be content with a three-layer governmental architecture. At the bottom, a layer made of many small governments each responsible for the provision terms of goods 1, 2 and 3. Fewer government units with larger jurisdictions would make up an intermediate layer, with each unit responding for the provision terms of goods 4 and 5. At the top, a single-government layer accountable for goods 6, 7 and 8 over the entire national territory. ${ }^{24}$ Curiously, this three-layer hypothetical architecture is often the governmental architecture actually found in many countries: one central government, up to a few tens of regional, state or provincial governments, and up to a few thousands of local, county, municipal or parochial governments. A fourth layer is increasingly evident in the European Union. In fact, following the principle of subsidiarity, Member States are transferring to an emerging supranational government (the Union) the provision terms of cross-border goods, like good 8 in Figure 17. Hence, federalism in public finance is a fact of life all over the world no matter how political federalism may lag behind the scene.

\section{Appendix-Partial Proof of Proposition 6}

In this section we prove the upward rotation of the $B$-curve in Figure 9, p. 16. The rest of the demonstration is on the main text, next to the proposition.

To begin with, the social gain associated to the spillover internalisation is traced back to the usual changes in consumers' surplus. This is done in Figure 18 below where a negative externality is illustrated-mutatis mutandis, the argument applies to positive externalities as well. The private marginal benefit enjoyed by $N$ individuals is represented by the negatively sloped curve $P M g B$. This schedule is the vertical aggregation of the $N$ individual demand curves $D_{j}(j=1, \ldots, N)$. For a constant social marginal cost (see curve

\footnotetext{
${ }^{24}$ For a formal analysis of this point, see Hochman et al. (1995). The authors combine space with the conventional analysis of local public goods provision to address the case where the market areas for different goods overlap. They show that the efficient outputs can be decentralised through local authorities having
} 
$S M g C$ ), the private optimum requires the provision of $g^{p}$ units of the public good. However, the remaining population, i.e., the individuals external to the $N^{\text {th }}$-sized club do not esteem this good, as is understood by their collective negative marginal benefit-curve $D_{-N}$. Hence, the aggregate marginal benefit corresponding to all (internal and external) consumers is given by the social marginal benefit $(S M g B)$ curve. Note that this curve lies below the private marginal benefit curve. Therefore, the socially optimal output $\left(g^{e}\right)$ is smaller than the private one $\left(g^{p}\right)$. The output cut to $g^{e}$ units improves net social benefit, or social welfare, by the shaded triangular area. This area is precisely the vertical distance between curves $B^{\prime}$ and $B$ for population size $N$ in Figure 9. The greater the externality (i.e., the larger the triangular area in Figure 18), the higher is the distance between curves $B^{\prime}$ and $B$.

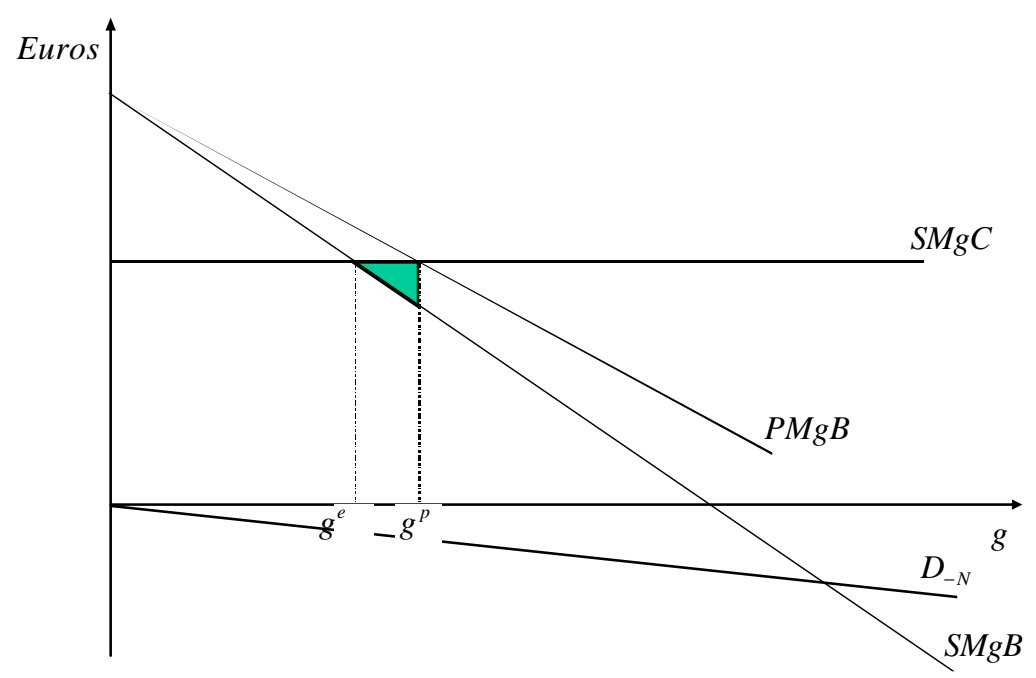

Figure 18-The welfare gain from the internalisation of external consumers

\section{References}

Baleiras, Rui N. (2001), The Economics of Multilevel Governance, mimeo, Lisbon: Universidade Nova de Lisboa, Faculdade de Economia.

Bardhan, Pranab and Mookherjee, Dilip (1999), Relative Capture of Local and Central Governments: an Essay in the Political Economy of Decentralization, Working Paper Series No. C99-109, December, Berkeley (USA): University of California, Berkeley, Center for International and Development Economics Research (CIDER).

Footnotes, continued from previous page

jurisdiction over the set of all market areas. An implication of their analysis is that a single, metropolitan government should be enacted to provide all those local public goods-a multifunction government, after all. 
Baumgardner, James R. (1993), "Tests of Median Voter and Political Support Maximization Models: the Case of Federal/State Welfare Programs", Public Finance Quarterly, Vol. 21 (1), January, pp. 48-83.

Buchanan, James (1965), “An Economic Theory of Clubs”, Economica, Vol. 32 (125), February, pp. 1-14.

Dougan, William R. and Kenyon, Daphne A. (1988), "Pressure Groups and Public Expenditures: the Flypaper Effect Reconsidered", Economic Inquiry, Vol. 26 (1), January, pp. 159-170.

Hochman, Oded, Pines, David, and Thisse, Jacques-François (1995), "On the Optimal Structure of Local Governments", The American Economic Review, Vol. 85 (5), December, pp. 1224-1240.

Krueger, Anne O. (1974), "The Political Economy of the Rent-Seeking Society", The American Economic Review, Vol. 64 (3), June, pp. 291-303.

Oates, Wallace E. (1972), Fiscal Federalism, New York: Harcourt Brace Jovanovich, Inc.

Olson, Mancur (1969), "The Principle of 'Fiscal Equivalence': the Division of Responsibilities Among Different Levels of Government", The American Economic Review, Vol. 59 (2), May, pp. 479-487.

Renaud, Paul and van Winden, Frans (1991), "A Theoretical Model of a Multi-Level Government Applied to The Netherlands", in Rémy Prud'homme (ed.), Public Finance with Several Levels of Government, Proceedings of the 46th Congress of the International Institute of Public Finance, held in Brussels, August 1990, The Hague (The Netherlands) and Koenigstein (Germany): Foundation Journal Public Finance, pp. 263-277.

Tiebout, Charles M. (1956), “A Pure Theory of Local Expenditures”, Journal of Political Economy, Vol. 64 (5), October, pp. 416-424.

Tullock, Gordon (1967), “The Welfare Costs of Tariffs, Monopolies and Theft", Western Economic Journal, Vol. 5, June, pp. 224-232.

Varian, Hal R. (1992), Microeconomic Analysis, third edition, International Student Edition, New York: W.W. Norton \& Company. 